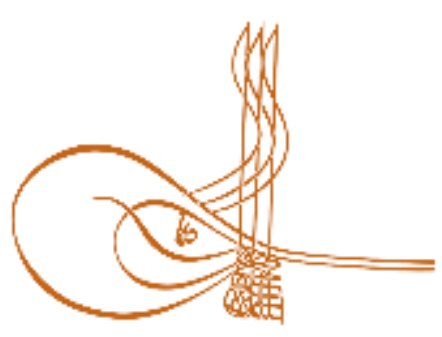

www.turkishstudies.net/social
Turkish Studies - Social Sciences

eISSN: $2667-5617$

Research Article / Araștırma Makalesi

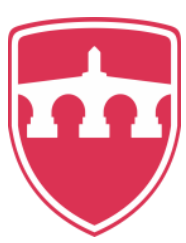

INTERNATIONAL

BALKAN

UNIVERSITY

Sponsored by IBU

\title{
Siyasal İletişimde Yeni Bir Ortam ve İmkân Olarak Sosyal Medya Mitingi: 2019 Yerel Seçimleri Uygulama Örneği
}

\author{
Social Media Meeting as a New Environment and Opportunity in Political Communication: \\ Example of Implementing the 2019 Local Elections
}

\author{
Bahar Yalın* - Recep Çolak ${ }^{* *}$
}

\begin{abstract}
Social media tools have become an indispensable element of social life, public opinion and politics. Political actors commonly use social media tools to inform voters, to establish simultaneous and bidirectional communication and to create public opinion, especially during the election campaign periods. This feature of social media has brought new possibilities of use for political communication. Social media meetings are distinguished from traditional meetings, one of the first forms of political communication that took place during the political campaign period, with an independent and mediated communication feature. Social media meetings provide an environment and opportunity for individuals addressed by political institutions and individuals to convey their own political views through instant and mutual communication, close convergence by removing significant barriers with large masses, create public opinion, provide clear answers to individuals' questions, and establish a rapid organization network. This research aims to reveal the effects of social media meetings on political participation and political communication through a new environment and possibility. The fact that the existing literature on political meetings is extremely inadequate, and the lack of published studies on social media meetings show the original value of the study, and it is thought that this study will make an important contribution to the relevant literature. Within the scope of the research, social media meetings organized through Facebook with the participation of candidates for Mayor of Erzurum Metropolitan, Kocaeli Derince, Kocaeli Körfez, Kocaeli Metropolitan, Samsun Atakum, Samsun Metropolitan, Trabzon Metropolitan, Yalova Kaytazdere were discussed in the 2019 Local Elections. Accordingly, 8 social media meetings videos and 3919 comments were reviewed in 11 categories. Content analysis method was used in the analysis of the obtained data. Based on the analyzed social media rallies and analyzes, it was concluded that social media rallies provide the necessary environment to influence a large number of voters with less effort and cost than traditional rallies, provide opportunity for
\end{abstract}

* Prof. Dr., Trabzon Üniversitesi, İletişim Fakültesi, Halkla İlişkiler ve Reklamcilık Bölümü
Prof. Dr. Trabzon University, Faculty of Communication, Department of Public Relations and Advertising
ORCiD 0000-0003-4619-3584
baharerogluyalin@ gmail.com.
${ }^{* * *}$ Yüksek Lisans Öğrencisi, Trabzon Üniversitesi.
Graduate Student, Trabzon University
ORCiD0000-0002-1254-7885
recepcolakk7@ gmail.com
Cite as/ Atıf: Yalın, B., Çolak, R. (2020). Siyasal iletişimde yeni bir ortam ve imkân olarak sosyal medya mitingi:
$2019 \quad$ yerel seçimleri uygulama örneği, Turkish Studies - Social, 15(1), 753-766. https://dx.doi.org/10.29228/TurkishStudies.40084

Received/Geliş: 09 December/Aralık 2019

Accepted/Kabul: 25 February/Şubat 2020

Checked by plagiarism software

Copyright $($ INTAC LTD, Turkey

Published/Yayın: 29 February/Şubat 2020

CC BY-NC 4.0 
candidates and voters to establish intimacy, and provide candidates with the opportunity to evaluate the feedback from voters.

Structured Abstract: History is the communication of human beings with the world. While it is thought that every technological development in the process of human communication with the world will invalidate the previous one, it has actually transformed the existing and the same has remained the same. Since the 1950s, when the two computers talked to each other for the first time, the momentum of communication has also changed the means and environments. The course of democracy and thus political participation from the ancient Greek agora to the internet has undergone a major transformation with the abolition of spatial and temporal limitations. In this study titled "Social Media Meeting As A New Environment And Opportunity In Political Communication: Example Of Implementing The 2019 Local Elections", social media meetings which are an example of this transformation were discussed.

The meeting, which is used as the equivalent of rally and meeting words in English, is used in Turkish with reference to its political content. According to the Turkish Language Association, meetings are usually organized in open spaces, unarmed, non-attacking, organized for demonstration purposes or to draw attention to an event. The definition refers to the nature of the meeting as open spaces. Meetings, which are a type of face-to-face political communication, are mostly political propaganda tools. It is aimed to convince the message of a unidirectional source to the audience gathered at the same time and place in a convincing manner and thus to affect the public. Political actors can now dominate the country's agenda in social networks such as Twitter and Facebook, using the advantages of social media, as well as traditional rallies held during election periods and they organize large masses of people around this agenda. With this method, actors who play a role in the political participation process can establish closer and sincere relations with their target groups and reach out to young people in particular.

With this research, it will be revealed how social media, which has an increasing impact on political life, and social media meetings, which is a new environment brought to politics, transform the dimensions of political communication and participation. For this purpose, in the context of 2019 Local Elections, Erzurum Metropolitan, Kocaeli Derince, Kocaeli Korfez, Kocaeli Metropolitan, Samsun Atakum, Samsun Metropolitan, Trabzon Metropolitan, Yalova Kaytazdere Mayor candidates are organized with the participation of Facebook social media meetings research group. In this context, 8 social media meetings videos and 3919 comments in 11 categories were analyzed and the data were obtained. Content analysis was used to analyze the data obtained after the comments made to social media meetings were written. In a study conducted by Bayraktutan et al. (2012) on Twitter, the subject of the posts and tweets were discussed in 27 different categories. These categories included statements that Supported Political Opponents, The Local Agenda Of The Constituency, Evaluation Of Agenda Items, Wishes For Elections, Wishes or Celebrations and other categories. In addition to these categories, Supporting Phrases, Opposition / Critical Phrases, Suggestion / Project / Demand Phrases, Tag (\#) Support Created by Party Organizations, Greeting, Technical Infrastructure categories were added to the study. In this context, the findings are divided into 11 categories.

In this study, it is aimed to draw attention to the increasing impact of social media on political life and to examine how social media meetings, a new environment brought by political communication to politics, bring innovation to political life and transform the dimensions of political communication and participation. Based on the social media meetings and analyzes analyzed in this context, it is seen that social media meetings provide the necessary environment to influence thousands of voters with less effort and cost to the traditional meetings. Social media meetings, by removing certain barriers to the public, enable the candidate and the voter to establish intimacy and thus undergo a more effective communication process and strengthen bilateral communication with its simultaneous structure. Moreover, when these meetings are evaluated in terms of political participation, they can turn individuals who have a tendency to participate in traditional meetings into active individuals with time, effort and cost advantages. Another important feature of social media meetings, which is not common in traditional meetings, is that it allows voters from different perspectives to be in the same environment, to express their opinions freely and to discuss each other. Social media rallies, on the other hand, provide candidates with the opportunity to evaluate the feedback from voters and to develop their projects and promises as a result of this assessment. It encourages the candidates to adopt a more level and consistent attitude and provide them with the opportunity to learn before the elections about how each movement and every word they make is perceived by the voters. Another important issue

Turkish Studies - Social, 15(1) 
that highlights social media meetings is that it has a structure that can contribute to the political socialization of young people and mobilize them.

Keywords: Political communication, political participation, political campaign, social media meetings.

Öz: Sosyal medya araçları, günümüzde toplumsal yaşamın, kamuoyunun ve siyasetin vazgeçilmez bir unsuru haline gelmiştir. Siyasal aktörler özellikle seçim kampanyası dönemlerinde seçmen kitlesini bilgilendirmek, eş zamanlı ve çift yönlü iletişim kurmak ve kamuoyu oluşturmak için sosyal medya araçlarını yaygın olarak kullanmaktadır. Sosyal medyanın bu özelliği siyasal iletişim için yeni kullanım olanaklarını da beraberinde getirmiştir. Siyasal kampanya döneminde gerçekleştirilen siyasal iletişimin ilk akla gelen biçimlerinden biri olan geleneksel mitinglerden, mekân bağımsız ve aracılandırılmış iletişim özelliği ile ayrılan sosyal medya mitingleri siyasal kurum ve kişilerin hitap ettiği bireylere anlık ve karşılıklı iletişimle kendi siyasal görüşlerini aktarma, geniş halk kitleleri ile arasındaki engelleri önemli düzeyde kaldırarak yakınlaşma, kamuoyu oluşturma, bireylerin sorularına içtenlikle, net cevaplar verebilme ve hızlı bir örgütlenme ağı kurabilmek için bir ortam ve imkân sunmaktadır. Bu araştırma, sosyal medya mitinglerinin siyasal katılım dolayısıyla siyasal iletişim üzerindeki etkilerini "yeni bir ortam ve imkân olma" sorunsalı üzerinden ortaya koymayı amaçlanmaktadır. Siyasal mitingler konusunda varolan literatür son derece yetersiz olması, sosyal medya mitingleri konusunda ise yayınlanmış çalışmanın olmaması çalışmanın özgün değerini göstermekte bu yönü ile çalışmanın ilgili literatüre önemli bir katkı sağlayacağı düşünülmektedir. Araştırma kapsamında 2019 Yerel Seçimlerinde Erzurum Büyükşehir, Kocaeli Derince, Kocaeli Körfez, Kocaeli Büyükşehir, Samsun Atakum, Samsun Büyükşehir, Trabzon Büyükşehir, Yalova Kaytazdere belediye başkan adaylarının katılımı ile Facebook üzerinden organize edilen sosyal medya mitingleri ele alınmıştır. Bu doğrultuda 8 sosyal medya mitingi videosu ve 11 kategoride toplam 3919 yorum incelenmiştir. Elde edilen verilerin çözümlenmesinde içerik analizi yöntemi kullanılmıştır. İncelenen sosyal medya mitinglerinden ve yapılan analizlerden hareketle sosyal medya mitinglerinin; geleneksel mitinglere göre daha az bir çaba ve maliyetle çok sayıda seçmeni etkilemek için gerekli ortamı sunduğu, aday ile seçmenin yakınlık kurmasına firsat tanıdığı, farklı görüşten seçmenlerle aynı ortamda bulunma, fikrini özgürce beyan etme ve karşılıklı tartışabilme olanağı sağladığı, adaylara, seçmenlerden gelecek geri bildirimleri değerlendirme ve bunun sonucunda projelerini ve vaatlerini seçim öncesinde geliştirme imkânı sunduğu sonucuna ulaşılmıştır.

Anahtar Kelimeler: Siyasal iletişim, siyasal katılım, siyasal kampanya, sosyal medya mitingleri.

\section{Giriş}

Tarih, insanın dünya ile kurduğu iletişimdir. İnsanın dünya ile kurduğu iletişim süreci içinde her teknolojik gelişmenin bir öncekini geçersiz kılacağı düşünülürken aslında yeni varolanı dönüştürmüş, özü itibarı ile eski aynı kalmıştır. İki bilgisayarın ilk kez birbiri ile konuştuğu 1950'li y1llardan günümüze iletişimin kazandığı ivme araçları ve ortamları da değişime uğratmıştır. Antik Yunan agoralarından internet ortamlarına demokrasi ve dolayısıyla siyasal katılımın seyri mekân ve zamansal sınırlılıkların kalkması ile büyük bir dönüşüme uğramıştır. "Siyasal İletişsimde Yeni Bir Ortam ve Imkân Olarak Sosyal Medya Mitingi: 2019 Yerel Seçimleri Uygulama Örneği”" başlıklı bu çalışmada bu dönüşümün bir örneği olan sosyal medya mitingleri ele alınmıştır. Çalışmanın Gelenekselden Dijitale Siyasal İletişim başlıklı birinci bölümünde siyasal iletişim tanımı, gelişim süreci, işlevleri tarihsel bağlamı ile ele alınmıştır. Seçim Kampanyaları Sürecinde Sosyal Medya Kullanımı bölümünde seçim kampanyaları türleri siyasal aktörler ve hedef kitle dolayımında ele alınmış, her iki unsurun birbiri ile etkileşimlerine olanak tanıyan sosyal medya araçları hakkında bilgi verilmiştir. Üçüncü kısımda sosyal medya mitingi siyasal katılımın yeni bir biçimi olabilir mi? Sorusu yanıtlanmaya çalışılmıştır. 2019 yerel seçimlerinde belediye başkan adaylarının gerçekleştirdiği siyasal mitingleri hedef kitle üzerindeki etkilere dair yapılan araştırmanın yöntem, bulgu ve yorumlarına dördüncü ve beşinci bölümlerde yer verilmiş, bulgular sonuç bölümünde tartışmaya açılmıştır. 


\section{Gelenekselden Dijitale Siyasal İletişim}

Siyasal iletişim özünde güç iletişimidir. Yöneten-yönetilen ayrımının doğması ile birlikte önde gidenlerin, takip edenleri etkileme, beğenilerini kazanma, onların bağlılıklarını kalıcı kılma ve varlıklarını meşrulaştırma istekleri siyasal iletişimin temel gerekçesini sunar. Aziz siyasal iletişimi, "siyasal aktörlerin belli ideolojik amaçlarını, politikalarını belli gruplara, kitlelere, ülkelere ya da bloklara kabul ettirmek ve gerektiğinde eyleme dönüştürmek, uygulamaya koymak üzere çeşitli iletişim tür ve tekniklerini kullanmaları" olarak tanımlar (2014: 3). Siyasal aktör derken aslında geniş anlamı ile devlet başkanları, hükümetler, siyasal partiler, yerel yönetimler, sivil toplum örgütleri, baskı grupları, terör grupları kastedilmektedir. Her bir aktör hedeflediği kitle ile kurduğu/kuracağı iletişim süreci ile ilgili olarak farklı tür ve tekniklere ihtiyaç duyar. Söz konusu tür ve teknikler siyasal iletişim uygulamalarının, içinde bulunduğu dönemin kültürel, toplumsal, ekonomik ve teknolojik birtakım gelişmeleriyle paralellik gösterir.

Yazının bulunması, matbaanın, telgrafin, radyo ve televizyonun icadı ve internetin kullanılmaya başlanması siyasal iletişim uygulamalarının genel teamüllerini etkileyen başlıca unsurlardır (Tokgöz, 2008). Bilgi, düşünce ve haberin kitleler üzerinde yaygınlık kazanmasını sağlayan matbaanın icadı, kitap ve gazetelerin yaygınlaşmasını sağlamış, telgraf teknolojisi ile önce sesi radyo ile ardından ses ve görüntüyü aynı anda televizyon ile aktarmak mümkün hale gelmiştir. İnternet ise tüm iletişim teknik ve türlerini hatta tüm iletişim devrimlerini içinde barındıran bir iletişim araç ve ortamı olarak yeni bir çağın başlangıcına işaret etmektedir. Dijitalleşme olarak genelleştirilebilecek internet teknolojileri anlık ve etkileşimli iletişimi mümkün hale getirerek sadece teknolojinin değil, kültürün, ekonominin toplumların sınırsız bağ kurabilmelerine olanak tanımıştır.

İnsanlık tarihinin tanık olduğu en büyük ve derin kitlesel yıkımlara neden olan iki dünya savaşının en önemli sonucu olan demokrasinin kazandığ 1 zafer sonrasında küreselleşme olarak adlandırılacak sınırsızlık hareketi rekabet, insan hakları, şeffaflık, açıklık gibi temel ilkelerin hızla yaygınlık kazanmasına neden olmuştur. Dahası belli aralıklarla yapılan seçimlerle yönetenler meşruiyetlerini sağlamak zorunda olduklarından siyasal iletişim sadece yönetenin kaynak durumunda olduğu sadece seçim dönemi ile sınırlı çizgisel ve tek yönlü bir süreç olmaktan çıkmış, sürekli ve sürdürülebilir kampanyalarla aralıksız işlemesi gereken bir içeriğe sahip olmuştur.

Bu noktada siyasal iletişimin üç temel işlevi yerine getirdiği söylenebilir: siyasal sorunların tanımlanmasına yardımcı olmak, siyasal sorunların tartışılarak meşruiyet kazanmasını sağlamak, tartışma konusu olmaktan çıkmış, görüş birliğine varılmış konuları gündemden düşürmektir (Wolton, 1990; Akt. Özkan, 2004: 40). Siyasal iletişim fonksiyonları, daha geniş bir bağlamda incelendiğinde ise yedi temel özellik ön plana çıkmaktadır. Bunlar; siyasal mesajların aktarılması, mesajların etkinliğinin ve kalıcılığının artırılması, kamuoyu beklentilerinin ölçümlenebilmesi, geri besleme kanallarının tesisi, kanaat önderlerinin etkilenmesi, gündem oluşturabilme yeteneğinin artırılması ve son olarak siyasal rakiplere karşı avantaj sağlanması şeklinde sıralanabilir (Özkan, 2004: 41). Tüm yönetim sistemlerinde siyasal iletişim gerçekleştirilir fakat meşruiyetini toplumsal rızanın sağlanmasından alan, seçebilmeyi mümkün kılan bir sistem olarak demokrasi siyasal iletişimin tüm işlev ve özellikleri ile etkin ve etkili olmasında en elverişli iklimi oluşturur.

\section{Seçim Kampanyaları Sürecinde Sosyal Medya Kullanımı}

Seçim kampanyaları; ülke çapında ya da ülkenin belirli bölgelerinde yapılan seçimlerde, siyasal partiler tarafından belirlenen adayların, seçimleri kazanmak amacıyla yürüttükleri çalışmalarda kullanılan teknik ve yöntemlerin tamamıdır. Seçmen kitlesine yönelik gerçekleştirilen seçim kampanyalarının nihai amacı iktidarı elde etmektir (Yalın, 2009: 200). Bu nihai amacın gerçekleşmesi için ise seçim kampanyası olarak tanımlanan dönemlerde farklı seçmen kitlesine yönelik stratejiler belirlenerek, bu stratejilere uygun kampanya uygulamaları gerçekleştirilir. 
Seçim kampanyalarında genel olarak üç tür seçmen kitlesi esas alınır ve bu seçmen kitleleri aynı zamanda seçim kampanyalarının türlerini de tanımlamaktadır (Aziz, 2014: 113-114). Kararlı seçmen, bir siyasal parti için en güvenilir seçmen kitlesidir. Bu kitleye yönelik oluşturulacak mesajlarda onun güvenini tazeleyecek, yeni programlar sunacak bir söylem yeterli olabilir. İkincisi kararsız seçmene yönelik kampanyalardır. Bu kampanya türünün asıl amacı, kampanyanın son günlerine kadar hangi partiye oy vereceği belli olmayan kararsız seçmen üzerinde etkili olmak ve kampanyası yapılan partiye oy verilmesini sağlamaktır. Üçüncü kampanya türü ise ilgisiz seçmene yönelik kampanyalardır. Bu kampanya türünde ise sandık başına gitmeyen ilgisiz seçmen kitlesini seçimler konusunda duyarlı hale getirip sandık başına gelmesini ve kampanyası yapılan partiye oy vermesini sağlamaktır (Çetin, 2017).

Kararl1, kararsız ve ilgisiz seçmen kitlesine yönelik kampanyalar için günümüzün en etkili araçlarından biri de hiç kuşkusuz sosyal medyadır. Sosyal medya, bireylerin internet kaynakları üzerinden oluşturdukları sanal hesaplar ile düşünce ve fikir üretebildikleri, bu içerikleri paylaştıkları sanal tartışma platformları (Doğan, 2019) olarak tanımlanabilir. Sosyal medya zaman ve mekân sınırlaması bulunmayan, etki gücü yüksek olan, büyük kitleleri kısa sürede organize edebilen, paylaşımın, tartışmanın ve değerlendirmenin esas olduğu bir iletişim şeklidir (Vural ve Bat, 2010).

Kullanılmaya başlandığı ilk zamanlarda haber alma gibi basit bir iletişim fonksiyonuna sahip olan sosyal medya araçları; özellikle Facebook, Twitter vb. uygulamaların yaygınlaşması ile artık sosyal bir iletişim ve etkileşim aracı haline gelmiştir. Sosyal medya kavramının yaşamımızı etkilemesi ile toplumsal sistem içindeki aktörler ve ilişki yapıları boyut, işlev ve söylem değiştirmeye başlamıştır. Sosyal medya araçlarına baktığımızda temel olarak sosyal ağ siteleri, bloglar, mikrobloglar, içerik paylaşım siteleri, wikiler ve forumlar karşımıza çıkmaktadır. Sosyal ağ siteleri, kullanıcıların kişisel bilgilerinin yer aldığı profil sayfaları oluşturmalarına imkân tanıyan, bu profil sayfalarına arkadaşlarını veya meslektaşlarını davet ederek ve birbirlerine e-posta veya anlık mesajlar göndererek bağlantılı hale gelmelerini sağlayan çevrimiçi iletişim sistemleridir. $\mathrm{Bu}$ kişisel profil sayfaları; fotoğraf, video, müzik ve bloglar gibi çeşitli türde bilgiyi içerebilmektedir (Kaplan ve Haenlein, 2010). Sosyal ağ siteleri, eş zamanlı etkileşime olanak tanıyan yapılarıyla bilginin dağıtımında ve ağızdan ağza iletişimde önemli bir rol oynamaktadır (Consantinides, 2009: 270). Sosyal ağ siteleri denilince ilk akla gelen Facebook, Twitter, Instagram vs.dir. Bloglar, Web 2.0 uygulamalarının en bilinen ve en hızlı büyüyen kategorilerinden biridir (Constantinides ve Fountain, 2008). Bloglar, bir günlük biçiminde sunulan web siteleri ya da çevrimiçi günlükler olarak bilinmektedir. (Bell, 2009). Mikroblog, bireylerin cep telefonlarını veya bilgisayarları aracılı̆̆ ile o anda yapmakta olduklarıyla ilgili internet üzerinden kısa mesajlar yayınlamalarına olanak tanıyan bir uygulamadır. Mikroblog uygulaması; blog, anlık mesaj ve durum güncelleme gibi unsurları buluşturan karma bir iletişim yöntemidir. Buna olanak sağlayan olgu da, katılım ve geribildirime dayalı akıcı bir sosyal ağ içerisinde bu tür kısa güncellemeleri yayımlamanın kolaylığıdır (Passant ve diğ., 2008: 2). Bireylerin kısa metin gönderileri vasıtasıyla arkadaşları ile güncel bağlantıda kalmalarına imkân tanıyan mikroblog uygulamasında kısa mesajlar 140-200 karakter aralığında sinırlandırılmaktadır (Akar, 2010: 55). Multimedya içeriklerinin saklanmasını ve paylaşılmasını mümkün kılan içerik paylaşım siteleri, sosyal medya araçları arasında en hızlı şekilde büyüyen alanlardan biridir. Video ve fotoğraf gibi içeriklerin paylaşıldığ 1 ve saklandığı bu popüler siteler, bireylerin sadece içerikleri tüketen değil, aynı zamanda aktif olarak web içeriğinin üretimine katkıda bulunan bireyler olmalarını ve bunun da kitlesel ölçekte gerçekleşmesini sağlamaktadır. Bunun sayesinde milyonlarca insan, kendi videolarını ya da fotoğraflarını üretebilmekte ve paylaşabilmektedir (Anderson, 2007: 10). İnsanların kolaylıkla ve ücretsiz olarak resim ve video gibi içerikleri yayımlamasına imkân veren içerik paylaşım sitelerinin en önemli özelliklerinden biri, içeriklerin düzenlenmesi ve yüklenmesi konusunda özel bir teknik bilgi gerektirmemesidir (Akar, 2010: 93). Wiki, ilk defa 1995 senesinde "WikiWikiWeb" adıyla Ward Cunningham tarafindan geliştirilen bir yazılımdır. En basit tanımıyla 
sıradan bir web sitesi gibi okunabilen, erişim için bir ayrıcalık gerektirmeyen ve asıl gücünü grupların standart bir web tarayıcısından başka bir şey kullanmalarına gerek kalmadan içerik üzerinde iş birliği halinde çalışabilmelerinden alan bir uygulamadır. Wikiler, site moderatörünün isteğine bağlı olarak herkesin düzenlemesine açık olabilmekte, kullanım kolaylığı sayesinde herhangi ayrıntılı bir teknik bilgi ya da araca gerek duyulmaksızın içerik yaratımı ya da içerik üzerinde düzenleme yapabilmeyi mümkün kılmaktadır (Bell, 2009: 143-144). Sosyal medya platformu örneği olarak ele alınabilecek forumlar ise, kullanıcıların belirli konulardaki deneyimlerini, fikirlerini ve bilgilerini diğer kullanıcılar ile paylaşabildikleri etkileşimli çevrimiçi ortamlardır (Bickart ve Schindler, 2001: 32). Forumlar, toplulukların genellikle konu başlıkları biçiminde düzenlenen mesajlar gönderme yoluyla bilgi değiş tokuşunda bulunabilmeleri için oluşturulan bir mekanizmadır (Pitta ve Fowler, 2005: 266). Forumların odak noktası, bir ürün ortaya çıkarmaktan ziyade, diyalogdur. Dolayısıyla forumlar, kişilerin bir fikir veya bir konu üzerinde tartışmaları için en uygun araçlar olarak görülebilir (Bell, 2009: 147). Tüm bu sosyal medya araçları bireyin, halkın ve siyasal aktörlerin kamuoyu ile ilişkisini geri dönülmez bir şekilde değişime uğratmıştır.

Sosyal medyanın sunmuş olduğu çok fazla bilgiye daha az sürede ulaşma gibi imkânlar sayesinde kamuoyu ile arasındaki bağ kuvvetlenmiştir. Örneğin kendini güçsüz olarak gören gruplar ve siyasal yaşamda varlığından söz edilemeyen bireyler sosyal medya sayesinde seslerini duyurabilmekte, kendi siyasi düşünceleri çevresinde destekçi toplayabilmekte ve böylece siyasal yaşamda dikkatleri üzerlerine çekebilmektedirler. $\mathrm{Bu}$ durum siyasal yaşam için çok önemli olan katılımcı demokrasiye önemli katkılar sunmakta ve uygulamada karşılaşılan sorunlar sosyal medya vasıtasıyla en aza indirgenmektedir (Köseoğlu ve Al, 2013: 122).

Sosyal medya, kamusal alanı ve siyaseti belirli bir dönüşüme tabi tutarak gündelik yaşamda bir araya gelmesi mümkün olmayan nitelik ve nicelikte farklı kesimlerden milyonlarca insanı bir fikir çatısı altında birleştirmesi; bu çatının altındaki yapıyı yönetmekte ve yönlendirebilmekte (Yağmur, 2015: 3), gerek siyasal aktörler gerekse hedef kitleler açısından birçok kullanım kolaylığ1 sunmaktadır. Sosyal medyanın geleneksel siyasal iletişim araçlarına göre öne çıkan önemli avantajlarının başında bu yöntemin geleneksel propaganda araçlarına göre çok daha düşük maliyetli olması gelmektedir (Wolfsfeld ve di ̆. ., 2013: 3). Sosyal medyanın süre açısından avantajı ise hedef kitleden alınacak tepkilerin tespitinin önceden sağlanmasıdır. Böylelikle siyasal aktörler, hedef kitlenin tepkilerine göre ya mesajlarında israrcı olmakta ya da stratejilerini kolaylıkla değiştirebilmektedir. Ayrıca sosyal medyada kullanılan belirli teknik ve yöntemlerle mesajların doğrudan kriterleri belirlenmiş hedef kitlelere ulaşması da sağlanabilmektedir. Örneğin sadece gençlere, sadece kadınlara, sadece belirli yaşın üzerindekilere veya sadece belirli bir bölgede oturanlara yönelik mesajlar geliştirilebilmekte, dahası sosyal medya bireylerin siyasal ilgisinin artmasına pasiflikten aktif vatandaş haline dönüşmesine katkı sağlamaktadır. (Köseoğlu ve Al, 2013: 118).

Geleneksel siyasal iletişim araçlarının birçoğu siyasal otoriteler tarafından rahatlıkla kontrol altına alınabildiği ve manipülasyona açık olduğu için muhalefet tarafından çok fazla kullanılamıyor, siyasal iktidarlar tarafından muhalif düşünceler kolaylıkla bastırılabiliyordu. Sosyal medyanın bir siyasal iletişim aracı olarak kullanılmasının önemli avantajlarından bir diğeri ise katılımcı demokrasiyi kapsamasıdır. Özellikle temsili demokraside aşılması zor sorunların başında gelen katılım sorunu, sosyal medya ile önemli ölçüde aşılabilmektedir.

Öte yandan sosyal medya birtakım riskleri de bünyesinde barındırmaktadır. Sosyal medyanın siyasal propaganda ve katılım aracı olarak kullanılması; bireylerin kısmen savunmasız hale gelmesini, kolay takip edilebilir olmasını ve ayrıca sansüre maruz kalma sorununu da beraberinde getirmektedir (Wolfsfeld ve diğ., 2013: 5). Ayn1 zamanda sosyal medya ortaminda ciddi bir bilgi kirliliği yaratılarak seçmenlerin kafası da karıştırılabilmektedir. Uygulamada karşılaşılan bir diğer dezavantaj ise, sosyal medya aracılığıyla oluşturulan içeriklerin kötü niyetli 
kullanımlara açık olmasıdır. Kimlik tespitinin sıradan vatandaş tarafından mümkün olmadığ 1 bu durumlarda, dezenformasyon, yalan haber ve bilgilerle kitleler yönlendirilebilmekte, olumsuz sonuçlara sebebiyet verebilmektedir.

\section{Siyasal Katılımın Yeni Biçimi: Sosyal Medya Mitingi}

Siyasal iletişim amaca ve siyasal aktör ile hedef alıcının konumuna göre olmak üzere temelde iki şekilde gerçekleşir. Amaca göre siyasal iletişim kurum içi, ülke içi ve uluslararası iletişim olarak sınıflandırılır. Siyasal aktör ve hedef alıcının konumuna göre siyasal iletişim türleri ise yüz yüze siyasal iletişim ve uzaktan/araçlı siyasal iletişim olmak üzere ikiye ayrılmaktadır. Yüz yüze siyasal iletişim; mesajı veren kaynak ile alıcı hedef kitlenin aynı ortamda bulunduğu siyasal iletişim türüdür. $\mathrm{Bu}$ tür iletişimde mesajlar sözlü olarak verilir ve genellikle bu mesajların geribildirimi sınırlı da olsa anında alınabilir. Aynı mekânda olunması sebebiyle geribildirimin en çabuk alındığı siyasal iletişim türüdür (Kılıçaslan, 2013). Uzaktan/Araçlı Siyasal İletişim; siyasal söylemde bulunan kaynak ile mesaj alıcısının birbirlerini görme olanaklarının bulunmadığı durumlarda tercih edilen araçlı siyasal iletişim türüdür (Aziz, 2014: 46).

İngilizce buluşma, görüşme, toplantı sözcüklerinin karşıllı̆ı olarak kullanılan miting Türkçede siyasal içeriğine gönderme yapılarak kullanılır. Türk Dil Kurumuna göre mitingler 'gösteri amacıyla veya bir olaya dikkati çekmek için genellikle açık alanlarda yapılan', 'silahsız, saldırısız, teşkilatlı toplantılardır (www.tdk.gov.tr, Erişim Tarihi: 15.10.2019). Tanım, mitinglerin toplanma özelliğine açık alanlar olarak işaret etmektedir. Yüz yüze gerçekleştirilen bir siyasal iletişim türü olan mitingler, bu yönü ile daha çok bir siyasal propaganda aracıdır. Tek yönlü bir kaynağın aynı an ve mekânda toplanmış kitleye mesajını ikna edici bir şekilde aktarımı, dolayısıyla kamuoyunun ve kitlenin etkilenmesi amaçlanır (Kurtbaş, 2015: 28). Siyasal aktörler, seçim dönemlerinde geleneksel olarak yapılan mitinglerin yanı sıra artık sosyal medyanın avantajlarını kullanarak Twitter ve Facebook gibi sosyal ağlarda ülke gündemine hâkim olabilmekte ve bu gündem etrafinda geniş halk kitlelerini örgütlemektedirler. Bu yöntemle siyasi katılım sürecinde rol oynayan aktörler, hedef kitleleri ile daha yakın ve samimi ilişkiler kurabilmekte ve özellikle de gençlere ulaşabilmektedirler. Siyasal aktörleri sosyal medya kullanımına yönelten sebeplerin başında bu araçların gençler arasında yaygın ve etkin bir biçimde kullanılması gelmektedir. Gençler; geleneksel mitinglerin yanı sıra sosyal medyada politik görüşleri savunan, bu düşüncesini yaymaya çalışan, hızlı etkileşim sağlayan Facebook, Twitter, YouTube gibi sosyal medya sitelerinde siyasal katılım göstermektedirler. Bu durum politikacıları sosyal medyanın oluş̧urduğu yeni iletişim kanallarına, etkili iletişime yönlendirmektedir (Yağmur, 2015: 34). Sosyal medya mitingleri ayrıca politikacıları daha seviyeli ve tutarlı bir tutum sergilemeye yönelterek yaptıkları her hareketin, sarf ettikleri her sözün seçmen tarafinda nasıl algılandığı, sonuçlarının ne derece etkili olacağı konularında seçimler öncesinde öğrenme imkânı vermektedir.

Geleneksel siyasal iletişim araçlarından olan mitingler yüz yüze propaganda aracı olarak hedef kitleye ulaşma konusunda sınırlı bir ortam sağlıyordu. Dolayısıyla fiziki koşullar nedeniyle sınırlı sayıdaki hedef kitleye hitap edilebiliyordu. Oysa sosyal medya, eş zamanlı bir biçimde çok daha geniş bir kullanıcı kitlesine ulaşabilen, saklanabilir özelliğiyle uzun süre de etkisini sürdürebilen bir propaganda aracı olarak karşımıza çıkmaktadır. Sosyal medya mitingleri, siyasal kurum ve kişilere hitap ettiği her türlü görüșe mensup bireylere kendi siyasal sistemlerini anlatabilme, halkla aradaki engelleri kaldırarak yakınlaşma, kamuoyu oluşturma, geniş halk tabanlarıyla etkili iletişimi sağlama, bireylerin her sorusuna içtenlikle, net cevaplar verebilme ve hızlı bir örgütlenme ağı kurabilme imkânı sunmaktadır (Gürbüz ve İnal, 2004: 95). Sosyal medya mitingleri; geleneksel mitinglerin hedef kitle, fiziksel alan, ulaşım gibi kısıtlılıklarını ortadan kaldırarak bireysel katılımı üst düzeylere çıkarmıştır. Geleneksel mitinglere göre daha az bir maliyetle hızlı bir örgütlenme şekline sahip olan sosyal medya mitingleri, siyasal katılımın genişlemesini sağlamıştır.

www.turkishstudies.net/social 


\section{Yöntem}

\section{Araştırmanın Amacl}

$\mathrm{Bu}$ araştırma ile siyasal yaşam üzerinde etkisi giderek artan sosyal medyanın ve siyasete kazandırdığı yeni bir ortam olan sosyal medya mitinglerinin siyasal iletişim ve katılım boyutlanını nasıl dönüştürdüğü ortaya koyulacaktır.

\section{Araştırmanın Örneklemi}

2019 Yerel Seçimleri bağlamında; Erzurum Büyükşehir, Kocaeli Derince, Kocaeli Körfez, Kocaeli Büyükşehir, Samsun Atakum, Samsun Büyükşehir, Trabzon Büyükşehir, Yalova Kaytazdere belediye başkan adaylarının katılımı ile organize edilen Facebook sosyal medya mitingleri araştırma grubunu oluşturmaktadır. Bu kapsamda 8 sosyal medya miting videosu ve 11 kategoride toplam 3919 yorum incelenmiştir.

\section{Verilerin Analizi}

Bu araştırma kapsamında 2019 Yerel Seçimleri bağlamında yapılan sosyal medya miting videoları ve bu mitinglere katılan bireylerin yaptıkları yorumlar incelenerek verilere ulaşılmıştır. Öncelikle sosyal medya mitinglerine yapılan yorumlar yazıya döküldükten sonra elde edilen verilerin çözümlenmesinde içerik analizi kullanılmıştır.

İçerik analizinde yapılan işlem, birbirine benzeyen verileri belirli kavramlar ve temalar çerçevesinde bir araya getirmek ve bunları okuyucunun anlayabileceği bir biçimde düzenleyerek yorumlamaktır (Yıldırım ve Şimşek, 2016). İçerik analizini kısaca açılayacak olursak, "iletişim içeriğinin, genellikle önceden belirlenmiş sınıflamalar (kategoriler) çerçevesinde sistematik olarak incelenmesini sağlayan bir araştırma tekniğidir" (Geray 2004). Orhan Gökçe içerik çözümlemesinin amacının "kamusal alana yönelik üretilen ve kurgulanan metinleri çözümlemek" olduğunu belirtmektedir (2006: 20).

\section{Bulgular ve Yorum}

Bayraktutan ve diğerlerinin (2012) Twitter üzerinde yapmış oldukları bir çalışmada gönderi ve tweetlerin konusu 27 ayrı kategoride ele alınmıştır. Bu kategorilerden Siyasi Rakipleri Destekleyen İfadeler, Seçim Bölgesinin Yerel Gündemi, Gündem Konularını Değerlendirme, Seçime İlişkin Temenni, Dilek ya da Kutlamalar ve Diğer kategorileri alınmıştır. Bu kategorilere ek olarak; Destekleyici İfadeler, Muhalif/Eleştirel İfadeler, Öneri/Proje/Talep İçeren İfadeler, Parti Teşkilatları Tarafindan Oluşturulmuş Olan Tag (\#) Desteği, Selamlama, Teknik Altyapı kategorileri çalışmaya eklenmiştir.

$\mathrm{Bu}$ bağlamda elde edilen bulgular 11 kategoriye ayrilarak sunulmaktadır. Sosyal medya mitinglerine katılan bireylerin yapmış oldukları yorumlar aşağıdaki şekilde kategorize edilmiştir:

1. Destekleyici İfadeler

2. Muhalif/Eleştirel İfadeler

3. Öneri/Proje/Talep İçeren İfadeler

4. Siyasi Rakipleri Destekleyen İfadeler

5. Seçim Bölgesinin Yerel Gündemi

6. Gündem Konularını Değerlendirme

7. Seçime İlişkin Temenni, Dilek ya da Kutlamalar

8. Parti Teşkilatları Tarafindan Oluşturulmuş Olan Tag (\#) Desteği

9. Selamlama 


\section{Teknik Altyap1}

\section{Diğer}

Tablo 1: Destekleyici İfadeler

\begin{tabular}{lc}
\hline Sosyal Medya Mitingi & Yorum Sayıs \\
\hline Erzurum Büyükşehir Belediyesi & 58 \\
Trabzon Büyüksşehir Belediyesi & 7 \\
Samsun Atakum Belediyesi & 48 \\
Samsun Büyükşehir Belediyesi & 664 \\
Kocaeli Derince Belediyesi & 87 \\
Kocaeli Körfez Belediyesi & 36 \\
Kocaeli Büyükşehir Belediyesi & 354 \\
Yalova Kaytazdere Belediyesi & 100 \\
\hline Toplam & $\mathbf{1 3 5 4}$ \\
\hline
\end{tabular}

Sosyal medya mitingine katılan bireyler, tıpk1 geleneksel mitinglerde olduğu gibi desteklemiş oldukları siyasal aktörlerin moral ve motivasyonuna olumlu katkı sağlayacak yorumlarda bulunmuşlardır. Bütün kategoriler arasında en çok yorum yapılan kategori bu kategoridir.

Tablo 2: Muhalif/Eleștirel İfadeler

\begin{tabular}{lc}
\hline Sosyal Medya Mitingi & Yorum Sayısı \\
\hline Erzurum Büyükşsehir Belediyesi & 19 \\
Trabzon Büyükşehir Belediyesi & 9 \\
Samsun Atakum Belediyesi & 5 \\
Samsun Büyükşehir Belediyesi & 107 \\
Kocaeli Derince Belediyesi & 19 \\
Kocaeli Körfez Belediyesi & 0 \\
Kocaeli Büyükşehir Belediyesi & 49 \\
Yalova Kaytazdere Belediyesi & 9 \\
\hline Toplam & $\mathbf{2 1 7}$ \\
\hline
\end{tabular}

Sosyal medya mitingine katılan bireylerin pozitif etkileşimlerinin yanı sıra seçim çalışmalarına, vaatlere ve projelere ilişkin muhalif/ eleştirel ifadelerini de siyasi adaya aktarma imkânı bulabildikleri görülmektedir.

Tablo 3: Öneri/Proje/Talep İçeren İfadeler

\begin{tabular}{lc}
\hline Sosyal Medya Mitingi & Yorum Sayısı \\
\hline Erzurum Büyükşehir Belediyesi & 32 \\
Trabzon Büyükşehir Belediyesi & 31 \\
Samsun Atakum Belediyesi & 5 \\
Samsun Büyükşehir Belediyesi & 20 \\
Kocaeli Derince Belediyesi & 20 \\
Kocaeli Körfez Belediyesi & 15 \\
Kocaeli Büyükşehir Belediyesi & 70 \\
Yalova Kaytazdere Belediyesi & 9 \\
\hline Toplam & $\mathbf{2 0 2}$ \\
\hline
\end{tabular}

Bireylerin sosyal medya mitinglerinde, şehirlerindeki seçim projelerine dair merak ettiklerini ögrenmeye yönelik yorum yaptıkları görülmektedir. Ayrıca bu projelere yönelik önerilerini ve diğer taleplerini iletebilme imkânı da bulmuşlardır. Geleneksel mitinglerde sık rastlanmayan bu durum, siyasi adaylara vaatlerini, projelerini ve çalışmalarını seçmenlerin öneri niteliğindeki yorumlarını göz önünde bulundurarak seçim öncesinde değerlendirme ve çalışmalarında değişiklik yapabilme imkânı sunmaktadır. 
Tablo 4: Siyasi Rakipleri Destekleyen İfadeler

\begin{tabular}{lc}
\hline Sosyal Medya Mitingi & Yorum Sayısı \\
\hline Erzurum Büyükşehir Belediyesi & 0 \\
Trabzon Büyükşehir Belediyesi & 0 \\
Samsun Atakum Belediyesi & 0 \\
Samsun Büyükşehir Belediyesi & 174 \\
Kocaeli Derince Belediyesi & 0 \\
Kocaeli Körfez Belediyesi & 0 \\
Kocaeli Büyükşehir Belediyesi & 0 \\
Yalova Kaytazdere Belediyesi & 0 \\
\hline Toplam & $\mathbf{1 7 4}$ \\
\hline
\end{tabular}

Geleneksel mitinglerde, miting alanında fiziki olarak bulunan bireyler genellikle hitap eden siyasi adayı destekleyen kişilerden oluşmaktayken aynı ortamda farklı görüşe sahip bireyler var ise bile bu bireyler görüşlerini açık şekilde ifade edememektedir.

$\mathrm{Bu}$ anlamda sosyal medya mitinglerinin, birbirinden farklı siyasi görüşlere sahip bireylere aynı ortamda bulunabilme, fikirlerini özgürce beyan etme ve karşılıklı olarak tartışabilme imkânı sunduğu görülmektedir. Ayrıca "Siyasi Rakipleri Destekleyen İfadeler" kategorisinde sadece Samsun Büyükşehir Belediyesi sosyal medya mitinginde yorum yapıldığı dikkat çekmektedir. Bu bağlamda yapılan yorumlar incelendiğinde Samsun Büyükşehir Belediyesi sosyal medya mitinginde, siyasi rakibi destekleyen bireylerin planlı ve organize bir şekilde hareket ettiği söylenebilir.

Tablo 5: Seçim Bölgesinin Yerel Gündemi

\begin{tabular}{lc}
\hline Sosyal Medya Mitingi & Yorum Sayısı \\
\hline Erzurum Büyükşsehir Belediyesi & 33 \\
Trabzon Büyükşehir Belediyesi & 25 \\
Samsun Atakum Belediyesi & 4 \\
Samsun Büyükssehir Belediyesi & 10 \\
Kocaeli Derince Belediyesi & 43 \\
Kocaeli Körfez Belediyesi & 16 \\
Kocaeli Büyükşehir Belediyesi & 23 \\
Yalova Kaytazdere Belediyesi & 10 \\
\hline Toplam & $\mathbf{1 6 4}$ \\
\hline
\end{tabular}

Sosyal medya mitingine katılan bireylerin seçim bölgesinin yerel gündemi hakkındaki yorumları toplam yorum sayısı bağlamında değerlendirildiğinde bireylerin bu konuya ilişkin ilgi düzeylerinin yüksek olduğu görülmektedir.

Tablo 6: Gündem Konularını Değerlendirme

\begin{tabular}{lc}
\hline Sosyal Medya Mitingi & Yorum Sayısı \\
\hline Erzurum Büyükssehir Belediyesi & 0 \\
Trabzon Büyükşehir Belediyesi & 1 \\
Samsun Atakum Belediyesi & 0 \\
Samsun Büyükssehir Belediyesi & 3 \\
Kocaeli Derince Belediyesi & 1 \\
Kocaeli Körfez Belediyesi & 1 \\
Kocaeli Büyükşehir Belediyesi & 8 \\
Yalova Kaytazdere Belediyesi & 0 \\
\hline Toplam & $\mathbf{1 4}$ \\
\hline
\end{tabular}

Seçmenlerin gündem konularını değerlendirme hususunda ilgilerinin çok düşük olduğu görülmektedir. Seçmenlerin, genel gündem konularından ziyade seçim bölgesinin yerel gündemi ile daha çok ilgilendiği söylenebilir. 
Sosyal Medya Mitingi

Tablo 7: Seçime İlişkin Temenni, Dilek ya da Kutlamalar

Erzurum Büyükşehir Belediyesi

Trabzon Büyükşehir Belediyesi

Samsun Atakum Belediyesi

Samsun Büyükşehir Belediyesi

Kocaeli Derince Belediyesi

Kocaeli Körfez Belediyesi

Kocaeli Büyükşehir Belediyesi

Yalova Kaytazdere Belediyesi

Toplam

$\mathrm{Bu}$ kategoriye ilişkin yorumlara incelenen sosyal medya mitinglerinin her birinde rastlanmaktadır. Bu kategoriye yapılan toplam yorum sayısına bakıldığında; genel yorum sayısı bağlamında yüksek bir orana karşılık gelmektedir. Bireyler, katılmış oldukları sosyal medya mitinglerinde siyasi adayların motivasyonunu artırmak amacıyla başarı temennisinde bulunmaktadırlar.

Tablo 8: Parti Teşkilatları Tarafından Oluşturulmuş Olan Tag (\#) Desteği

\begin{tabular}{lc}
\hline Sosyal Medya Mitingi & Yorum Sayısı \\
\hline Erzurum Büyükşehir Belediyesi & 0 \\
Trabzon Büyükşehir Belediyesi & 0 \\
Samsun Atakum Belediyesi & 0 \\
Samsun Büyükşehir Belediyesi & 46 \\
Kocaeli Derince Belediyesi & 153 \\
Kocaeli Körfez Belediyesi & 196 \\
Kocaeli Büyükşehir Belediyesi & 469 \\
Yalova Kaytazdere Belediyesi & 48 \\
\hline Toplam & $\mathbf{9 1 0}$ \\
\hline
\end{tabular}

Bu kategori incelendiğinde özellikle siyasi parti kadın ve gençlik teşkilatlarının sosyal medya mitingine yönelik önceden planlı ve stratejik bir hazırlık süreci yaşadığı ve mitinge yönelik ilgi seviyelerinin yüksek olduğu görülmektedir.

Tablo 9: Selamlama

\begin{tabular}{lc}
\hline Sosyal Medya Mitingi & Yorum Sayısı \\
\hline Erzurum Büyükssehir Belediyesi & 21 \\
Trabzon Büyükşehir Belediyesi & 3 \\
Samsun Atakum Belediyesi & 5 \\
Samsun Büyükşehir Belediyesi & 30 \\
Kocaeli Derince Belediyesi & 8 \\
Kocaeli Körfez Belediyesi & 2 \\
Kocaeli Büyükşehir Belediyesi & 30 \\
Yalova Kaytazdere Belediyesi & 11 \\
\hline Toplam & $\mathbf{1 1 0}$ \\
\hline & \\
\hline Sosyal Medya Mitingi & Yorum Sayısı \\
\hline Erzurum Büyükşehir Belediyesi & 12 \\
Trabzon Büyükşehir Belediyesi & 19 \\
Samsun Atakum Belediyesi & 2 \\
Samsun Büyükşehir Belediyesi & Tablo 10: Teknik Altyap1 \\
Kocaeli Derince Belediyesi & 5 \\
Kocaeli Körfez Belediyesi & 16 \\
Kocaeli Büyükşehir Belediyesi & 1 \\
Yalova Kaytazdere Belediyesi & 10 \\
\hline Toplam & 2 \\
\hline
\end{tabular}

www.turkishstudies.net/social 
$\mathrm{Bu}$ kategoride, sosyal medya mitingine katılan bireylerin, miting başlamadan önce veya miting sırasında yaşanan aksaklıklara yönelik çeşitli yorumlar yaptığı görülmektedir. Mitingi düzenleyen ve teknik altyapıdan sorumlu olan kişilerin bu yorumları değerlendirerek yaşanan aksaklıklara müdahale edebilme, durumu düzeltebilme firsatına sahip olabilmektedirler.

Tablo 11: Diğer

\begin{tabular}{lc}
\hline Sosyal Medya Mitingi & Yorum Sayısı \\
\hline Erzurum Büyükşehir Belediyesi & 28 \\
Trabzon Büyükşehir Belediyesi & 32 \\
Samsun Atakum Belediyesi & 33 \\
Samsun Büyükşehir Belediyesi & 110 \\
Kocaeli Derince Belediyesi & 144 \\
Kocaeli Körfez Belediyesi & 60 \\
Kocaeli Büyükşehir Belediyesi & 53 \\
Yalova Kaytazdere Belediyesi & 26 \\
\hline Toplam & $\mathbf{4 8 6}$ \\
\hline
\end{tabular}

Sosyal medya mitingine katılan bireylerin siyasi adaya yönelik yorumlarının yanı sıra kendi aralarında da etkileşime girdikleri ve birbirlerine yorum yaptıkları görülmektedir. Bireylerin, siyasi adaya yönelik yorumlarında emojileri de kullandıkları görülmektedir.

\section{Sonuç}

Küreselleşen dünya ile birlikte teknolojik gelişmelerin, gelişen kitle iletişim araçlarının ve enformasyonların siyasal iletişim sürecinde ve seçmen kanaatleri üzerinde etkili olduğunu söyleyebiliriz. Siyaset ve medya arasındaki ilişki her zaman önemli tartışma konusu olmuştur. Siyasetin, siyasi partilerin ve siyasilerin bulundukları arenada başarılı olmaları için bir kamuoyu desteğini almaları gerekliliği yadsınamaz bir gerçektir. Bu noktada özellikle sosyal medya, siyaset ve siyasi aktörler için önemli ve vazgeçilmez bir güç haline getirmiştir.

Sosyal medya, gün geçtikçe kullanıcı sayısını arttırmakta, etkileşim alanını genişletmekte ve siyaseti yönlendirmektedir. Siyasi kurumların ve siyasi liderlerin, sosyal medyanın gücünü kendilerine çevirme gayreti içinde olduklarını söylemek mümkündür. Yeni medyada düzen şeffaf ve çoğu durumlarda erişilebilir olduğundan, bu ortamın ciddiye alınması ve oluşan bu yeni ortamda yürütülen faaliyetlerin, ustalıkla yürütülmesi gerekliliğini ortaya çıkarmıştır. Bu algının etkisinin farkına varan siyasi iktidarların ve siyasi liderlerin algıyı kendilerinin yönetmesi ve böylelikle kamuoyunu arkasına alması, sosyal medyanın önemini göstermektedir.

Çalışmamızda sosyal medyanın siyasal yaşam üzerinde giderek artan etkisine dikkat çekilmesi; siyasal iletişimin siyasete kazandırdı ğ 1 yeni bir ortam olan sosyal medya mitinglerinin siyasal yaşama nasıl bir yenilik getirdiği, siyasal iletişim ve katılım boyutlarını nasıl dönüştürdüğünün irdelenmesi amaçlanmıştır. Bu bağlamda incelenen sosyal medya mitinglerinden ve yapılan analizlerden hareketle; sosyal medya mitinglerinin geleneksel mitinglere göze daha az bir çaba ve maliyetle binlerce seçmeni etkilemek için gerekli ortamı sunduğu görülmektedir. Sosyal medya mitingleri, halkla aradaki engelleri belirli düzeyde kaldırarak aday ile seçmenin yakınlık kurmasına ve dolayısıyla daha etkili bir iletişim süreci geçirmesine firsat tanımakta, eş zamanlı yapısı ile çift yönlü iletişimi güçlendirmektedir. Ayrıca bu mitingler siyasal katılım açısından değerlendirildiğinde geleneksel mitinglere katılma eğilimi düşük olan bireyleri zaman, çaba ve maliyet avantajları ile aktif bireyler haline getirebilmektedir. Sosyal medya mitinglerinin geleneksel mitinglerde pek rastlanmayan bir diğer önemli özelliği farklı görüşten seçmenlere aynı ortamda bulunabilme, fikrini özgürce beyan etme ve karşılıklı tartışabilme olanağı sağlamasıdır.

Diğer yandan sosyal medya mitingleri adaylara, seçmenlerden gelecek geri bildirimleri değerlendirme ve bu değerlendirme sonucunda projelerini ve vaatlerini geliştirme imkânı sunmaktadır. Adayları daha seviyeli ve tutarlı bir tutum sergilemeye yönelterek onları yaptıkları 
her hareketin, sarf ettikleri her sözün seçmen tarafindan nasıl algılandığı konusunda seçimler öncesinde öğrenebilme olanağı sağlamaktadır. Sosyal medya mitinglerini ön plana çıkaran bir diğer önemli husus özellikle gençlerin siyasal sosyalleşmesine katkıda bulunabilen ve onları mobilize edici bir yapıya sahip olmasıdır.

\section{Kaynakça}

Akar, E. (2010). Sosyal medya pazarlaması. Ankara: Efil Yayınevi.

Anderson, P. (2007). What is web 2.0? Ideas, technologies and implications for education, JISC Technology And Standards Watch, 1-64.

Aziz, A. (2014). Siyasal iletişim. Ankara: Nobel Yayınc1lık.

Bayraktutan G., Binark, M., Çomu T., Doğu B., İslamoğlu G. ve Aydemir, A. T. (2012). Sosyal medyada 2011 genel seçimleri: Nicel-nitel arayüzey incelemesi. Selçuk Illetişim Dergisi, $7(3)$.

Bell, A. (2009). Exploring web 2.0: second generation interactive tools, blogs, podcasts, wikis, networking, virtual worlds, and more. Georgetown: Katy Crossing Press.

Bickart, B. ve Schindler, R.M. (2001). Internet forums as influential sources of consumer information. Journal Of Interactive Marketing, 15(3), 31-40.

Constantinides, E. (2009). Social media / Web 2.0 as marketing parameter: An introduction. Paper presented at the International Marketing Trends Conference.

Constantinides, E. ve Fountain, S. J. (2008). Web 2.0: Conceptual foundations and marketing issues. Journal of Direct, Data and Digital Marketing Practice, 9(3), 231-244.

Çetin, S. (2017). Birleşik Krallık referandumu ve Türkiye tartışmaları: Vote leave negatif siyasal kampanyası örneği. Erciyes İletişim Dergisi, 5(2), 128-144.

Doğan, S. (2019). Sosyal medyanın kamuoyu oluşturmada kullanımı: 16 Nisan 2017 Anayasa değişikliği referandumu sürecinde siyasi aktörlerin sosyal medya paylaşımlarının içerik analizi. Erciyes Illetişim Dergisi, 6(1), 423-442.

Geray, H. (2004). Toplumsal araştırmalarda nicel ve nitel yöntemlere girişs-Illetişim alanından örneklerle. Ankara: Siyasal Kitabevi.

Gökçe, O. (2006). İçerik analizi: Kuramsal ve pratik bilgiler. Ankara: Siyasal Kitabevi.

Gürbüz, E. ve İnal, M. E. (2004). Siyasal pazarlama-Stratejik bir yaklaşım. Ankara: Nobel Yayın Dağıtım.

Kaplan, A.M. ve Haenlein, M. (2010). Users Of The World, Unite! The Challenges And Opportunities Of Social Media. Business Horizons, 53, 59-68.

Kılıçaslan, E. Ç. (2013). Siyasal iletişim, ideoloji ve medya iliş̧isi. Ankara: Paradigma Kitabevi Yayınları.

Köseoğlu, Y. ve Al, H. (2013). Bir siyasal propaganda aracı olarak sosyal medya. Akademik Incelemeler Dergisi, 8(3):103-125.

Kurtbaş, İ. (2015). Siyasi mitinglerin sosyo-politik analizi Adalet ve Kalkınma Partisi ile Milliyetçi Hareket Partisi mitingleri örneği. Karadeniz Uluslararası Bilimsel Dergi, 1(28), 39-62. doi:10.17498/kdeniz.97056. 
Miting. (t.y.). Türk Dil Kurumu güncel Türkçe sözlük içinde. Erişim adresi: http://www.tdk.gov.tr/index.php?option=com_yanlis\&view=yanlis\&kelimez=298

Özkan, A. (2004). Siyasal iletişim. İstanbul: Nesil Yayınları.

Passant, A., Hastrup, T., Bojars, U. ve Breslin, J. (2008). Microblogging: A semantic and distributed approach. In Proceedings of Workshop on Scripting for the Semantic Web.Erişim adresi: http://www.johnbreslin.com/files/publications/20080602_sfsw2008a.pdf

Pitta, D.A. ve Fowler, D. (2005). Internet community forums: An untapped resource for consumer marketers. Journal Of Consumer Marketing, 22(5), 265-274.

Tokgöz, O. (2008). Siyasal iletişimi anlamak. Ankara: İmge Kitabevi.

Vural, Z. ve Bat, M. (2010). Yeni bir iletişim ortamı olarak sosyal medya: Ege Üniversitesi İletişim Fakültesine yönelik bir araştırma. Journal of Yaşar University, 20(5).

Wolsfeld, G., Segev, E. ve Sheafer, T. (2013). Social media and the Arab spring: politics comes first. The International Journal of Press/Politics, 18(2), 115-137.

Yağmur, H. (2015). Sosyal medyanın siyaset ve kamuoyunu yönlendirmedeki rolü (Yayımlanmamış Yüksek Lisans Tezi). Selçuk Üniversitesi Sosyal Bilimler Enstitüsü, Konya.

Yalın, B. (2009). Siyasal değer: Siyasal O/A/Lanın iletişimi ve değer kabul ettiklerimiz. İstanbul: Derin Yayınları.

Yıldırım, A. ve Şimşek, H. (2016). Sosyal bilimlerde nitel araştırma yöntemleri (10. baskı). Ankara: Seçkin Yayıncılık. 